\title{
Application of an Aqueous Two-Phase Technique for Extraction of Papain from Carica Papaya Latex
}

\author{
Thato T. Tswiio, Orose Rugchati*,Duangporn Premjet and Niran Aeksiri
}

\begin{abstract}
An aqueous two phase system made up of polyethylene glycol (PEG) 3350 and potassium citrate was used to extract papain from papaya latex. The assessment of system parameters: PEG 3350, potassium citrate and sodium chloride concentrations on papain purification were studied. The enzyme partitioned preferentially to the bottom phase in all the experiments. Increasing sodium chloride up to $5 \%$ increased purification of papain. The highest purification (12 fold) was achieved using potassium citrate $20 \%$ - PEG14\% at $\mathrm{pH} 7$ and $4{ }^{\circ} \mathrm{C}$. This study showed that an environmentally friendly extraction system for papain can be developed and further optimized.
\end{abstract}

Keywords - aqueous two phase system, papain, purification factor

\section{INTRODUCTION}

PAPAIN (E.C 3.4.22.2) is a cysteine protease enzyme found in the latex and leaves of the Carica papaya plant. It contains 212 amino acid residues and has a molecular mass of 23406 Dalton [1]. This enzyme has found a wide usage in many applications such as human medicine, pharmaceuticals, tanneries, textiles, detergents, beauty therapies as well as food formulations [2]. Commonly, papain is extracted from the papaya plant latex, which also contains other protease enzymes such as chymopapain, glycyl endopeptidase and caricain [3]-[4]. The aqueous two phase system (ATPS) is an interesting liquid-liquid separation technique that can be used to clarify, concentrate and partially purify target biomolecules from their crude source [5] in just one step. The ATPS utilises cheap reagents, simple equipment, is quick and minimises denaturation of biomolecules [6], making it preferable for industrial enzyme harvesting. The global enzymes market was expected to reach $\$ 8.0$ billion by end of 2015 [7] showing a considerable contributor to world economy and their importance to industrial processes [8]. Reference [9] reports that the major enzymes used industrially are amylase, lipase, protease, ligase, phytase, cellulose, xylanase. Reference [8]

*Orose Rugchati is with the Agro-Industries Department, Faculty of Agriculture, Natural Resources and Environment of Naresuan University, Phitsanulok, 65 000,

Thato T. Tswiio is studying for a Master of Science degree at the Faculty of Agriculture, Natural Resources and Environment of Naresuan University, Phitsanulok, 65 000, Thailand.

Duangporn Premjet and Niran Aeksiri are both with the Agricultural Sciences Department, Naresuan University, Phitsanulok, 65000 Thailand. assets that carbohydrase, protease and lipase enzymes account for more than $70 \%$ of all sales world-wide. Almost all the enzymes are harvested from micro-organisms in bio-reactors. For ages papaya has been known as a cheap source of papain protease enzyme in which the enzyme harvesting does not affect the yield of fruit, providing an opportunity for adding value to papaya cultivation. The extraction and purification of such bioactive molecules from natural products and bioreactor fermentations has become one of the major concerns in biotechnology. Industry has employed various filtration, precipitation and liquid chromatography techniques over time to optimize the recovery of biomolecules with varying success. A good trade-off has to be made between the efficiency of these systems, their cost in time, equipment, energy, process complexity, environmental safety as well as suitability for up-scaling. In this light, a cheap, efficient, environmentally friendly and easy to scale-up technique such as the aqueous two-phase system is most relevant to be studied so as to increase the competitiveness of the biotechnology industry.

The goal of this work was to investigate and find the optimal conditions of primary extraction of papain enzyme from wet crude latex using the aqueous two phase technique. Purification factor/fold (PF) was taken as the main response variable while yield, specific activity (SA),partition coefficient (Kpap) and phase volume ratio $(\mathrm{Vr})$ of the papain were used as further indicators of efficiency of the technique. The concentration of the aqueous phase components, polyethylene glycol 3350, potassium citrate (K-citrate) as well as sodium chloride were used as independent variables.

\section{MATERIALS AND METHODS}

\section{A. Chemicals}

Polyethylene glycol (PEG) of average molecular mass 3350 and potassium citrate (K-citrate) were bought from Sigma Aldrich Co. and used without any further treatment.

\section{B. Raw material}

Latex used was collected and pooled from the Carica papaya local variety planted in Phitsanulok city. Latex was tapped from fruits before they matured. A sharpened wooden splint was used to make a few 1-2 mm deep vertical cuts into the green fruit and a plastic bag used to collect the dripping latex. The latex was stored at $-20^{\circ} \mathrm{C}$ until further use. 


\section{Preparation of crude latex solution}

The latex was thawed and mixed with 0.1 molar (M) phosphate buffer $(\mathrm{pH} \mathrm{7)}$ on a 1:1.5 weight/volume ratio following [10]. The mixture was well agitated for homogeneity before being centrifuged at $9000 \mathrm{x} \mathrm{g}$ for 30 minutes at $4^{\circ} \mathrm{C}$ to remove solids. The resultant supernatant was tested for protein content and protease activity before being used as latex solution in the ATPS experiments.

\section{Aqueous two phase extraction procedure}

A $10 \mathrm{ml}$ aqueous two-phase system was made with $20 \%$ (v/v) latex solution, different portions of PEG 3350 (10-20\%), potassium citrate $(14-20 \%)$, sodium chloride $(0-8.5 \%)$ and made up-to $10 \mathrm{ml}$ with $0.1 \mathrm{M}$ phosphate buffer $(\mathrm{pH} 7)$. The ATPS was mixed for 10 minutes before centrifuging at 9000 $\mathrm{x}$ g, 30 minutes at $4{ }^{\circ} \mathrm{C}$ to enable phase separation before pipetting each phase into a different test tube for further experiments.

\section{E. Analytical tests}

Protein concentration was measured using the Biuret test where 0.5 millilitre $(\mathrm{ml})$ aliquot of each of the phases was mixed with $4.5 \mathrm{ml}$ of Biuret reagent and incubated at 25 ${ }^{\circ}$ Celsius (C) for 20 minutes. A Genesys $20^{\mathrm{TM}}$ spectrophotometer (Thermo Scientific Inc.) set to $595 \mathrm{~nm}$ was used to measure absorbance using bovine serum albumin (BSA) as standard.

Papain enzyme activity was measured using the "universal protease activity assay" developed by Sigma Aldrich Inc.

\section{$F$. Determination of Kpap, $P F, S A$, Recovery and $V r$}

Partition co-efficient of papain was defined as the ratio of the volumetric activity of papain in the top phase (At) to that in the bottom phase $(\mathrm{Ab})$ :

$$
\text { kpap }=A t / A b
$$

Purification factor was defined as the activity of papain in the phase to which it partitioned (bottom phase) compared to the activity in the initial crude latex solution, measured in units per millilitre $(\mathrm{U} / \mathrm{ml})$ :

$$
P F=A b / A i
$$

Specific activity was defined as the ratio of papain activity in the bottom phase to protein content of the bottom phase, measured in units per milligram $(\mathrm{U} / \mathrm{mg})$ :

$$
S A=A b / \text { protein }
$$

Yield was defined as the ratio of papain activity $(\mathrm{Ab})$ of the bottom phase to the of initial papain activity (Ai) in the initial crude latex solution, measured in percentage:

$$
\text { Yield }=(A b / A i) x 100
$$

Phase volume ratio was defined as the ratio of top phase volume $(\mathrm{Vt})$ to that of the bottom phase $(\mathrm{Vb})$ :

$$
V r=V t / V b
$$

\section{G. SDS-PAGE analysis}

Sodium dodecyl sulphate-polyacrylamide gel electrophoresis using 5\% stacking and 12\% resolving gel, 120 $\mathrm{V}, 60$ minutes (Biorad Inc.) following [11] was utilized to confirm papain in the samples.

\section{H. Statistical analysis}

Analysis of variance was used to determine the influence, if any, of the aqueous two phase components on the purification factor of papain at $\alpha=0.05$. The relationship of the response variables and the fixed variables were shown using SPSS version 19 (IBM Inc.).

\section{RESULTS AND DISCUSSION}

In total, 390 grams of papaya latex was collected over 3 months. The protein content was found to be $39 \mathrm{mg} / \mathrm{g}$ of crude latex and enzymatic activity found to be $0.0335 \mathrm{U} / \mathrm{mg}$. The Fig. 1 below shows the two phases after separation by aqueous two phase system and their comparative volumes.

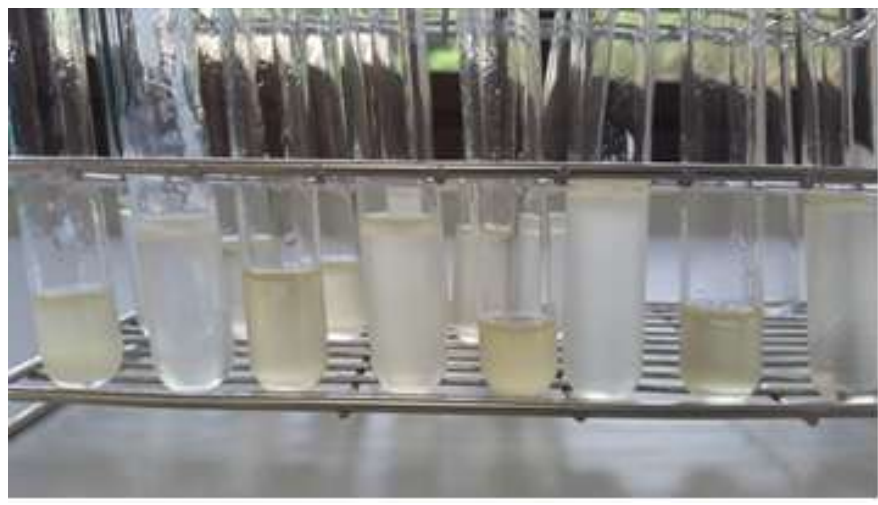

\begin{tabular}{|c|c|c|c|c|c|c|}
\hline & \multicolumn{5}{|c|}{ K-citrate $(\%)$} & \\
\hline & 14 & 16 & 18 & & 20 & \\
\hline & \multicolumn{6}{|c|}{ PEG (\%) } \\
\hline & 18 & 15 & 12 & 10 & 14 & 15 \\
\hline PF & 1.07 & 1.74 & 1.91 & 1.98 & 1.99 & 1.55 \\
\hline \pm & .002 & .008 & .205 & .004 & .012 & .007 \\
\hline \multirow[t]{2}{*}{ Yield $\%=$} & 63.29 & 69.57 & 78.89 & 71.36 & 74.17 & 59.17 \\
\hline & .229 & .191 & 1.401 & .157 & .112 & .145 \\
\hline
\end{tabular}

Fig.1 Top (PEG 3350) and bottom (K-citrate) phases from the aqueous two phase system

TABLE I. PURIFICATION OF PAPAIN EXTRACTED By AQUEOUS TwO PHASE WITH 0\% SODUIM CHLORIDE

According to Table I above, it can be seen that using the ATPS without any added sodium chloride, the purification increases only marginally and the yield is just below $80 \%$. The analysis of variation results proved that both potassium 
citrate and polyethylene glycol concentration had a significant effect on the purification factor $(\mathrm{p}<0.05)$.

TABle II Papain Purification From Aqueous Two Phase System Using $5 \%$ SODIUM CHLORIDE

\begin{tabular}{|c|c|c|c|c|c|c|c|c|}
\hline & \multicolumn{8}{|c|}{ K-citrate $(\%)$} \\
\hline & 14.00 & 15.00 & $\begin{array}{l}16.00 \\
\text { PEG } \\
\end{array}$ & \multicolumn{2}{|c|}{18.00} & \multicolumn{3}{|c|}{20.00} \\
\hline & 18.00 & 16.00 & 15.00 & 10.00 & 12.00 & 10.00 & 14.00 & 15.00 \\
\hline $\mathrm{PF}$ & 6.04 & 6.24 & 5.17 & 4.53 & 6.37 & 7.95 & 12.02 & 9.67 \\
\hline \pm & .017 & .039 & .004 & .003 & .029 & .101 & .023 & .054 \\
\hline \multirow{2}{*}{$\begin{array}{l}\text { Yield } \\
\% \pm\end{array}$} & 82.74 & 88.18 & 85.17 & 69.20 & 89.22 & 97.86 & 78.74 & 85.35 \\
\hline & .692 & .368 & .127 & .300 & 1.054 & .860 & .303 & .112 \\
\hline
\end{tabular}

The potassium citrate as well as PEG 3350 concentration was each found to have a significant effect on the purification factor (ANOVA table not shown). The results show that purification was increased 12 fold and $97.9 \%$ yield was achieved by adding 5\% sodium chloride to the ATPS. In contrast, Table III shows that while purification increased upto 9 fold, the yield decreased to below $65 \%$.

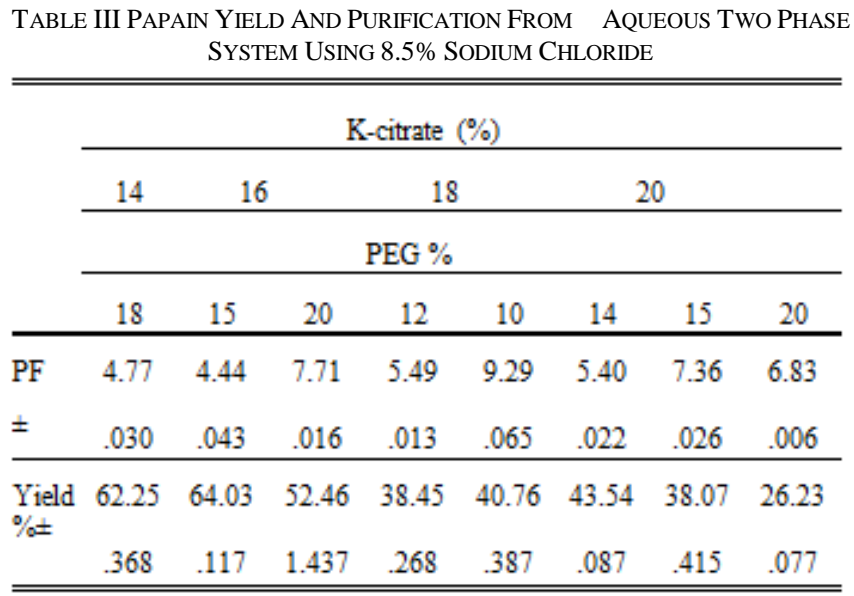

The results seem to suggest that $5 \% \mathrm{NaCl}$ is the optimal salt concentration to enhance both purification and yield of papain while $0 \%$ gives the lowest results. At $0 \%$ salt concentration, the aqueous two phase system does not have enough ionic strength to enhance isolation of the hydrophobic protein as observed also by [12], while at $8.5 \%$, the salt is too much and causes precipitation of the target protein causing lower yields, as also reported by [13].

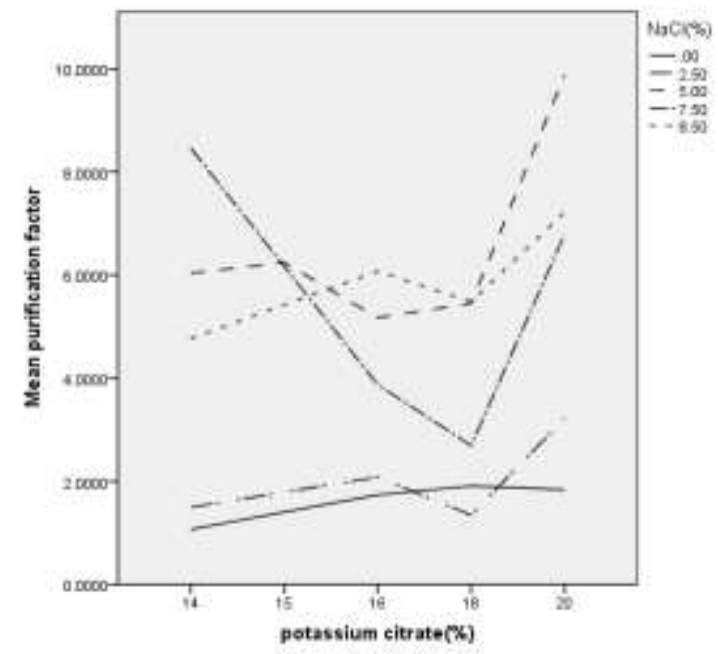

Fig.2. The effect of sodium chloride on the purification of papain using PEG $16 \%$

As can be seen in Figure 2, regardless of the potassium citrate concentration in the aqueous two phase system, the purification factor did not change much using $0 \%$ and $2.5 \%$ $\mathrm{NaCl}$. In contrast, at $5 \% \mathrm{NaCl}$ content, increasing the potassium citrate caused notable difference in the purification factor, with highest PF at K-citrate20\%-PEG16\%. Increasing the neutral salt above 5\% did not cause a better purification. A possible reason for these findings is that at lower concentrations $(0,2.5 \%) \mathrm{NaCl}$ did not contribute enough ionic strength into the system to affect the purification factor while at $7.5 \%$ and $8.5 \% \mathrm{NaCl}$ contents, the system salted-out the papain out and also reduced purification.

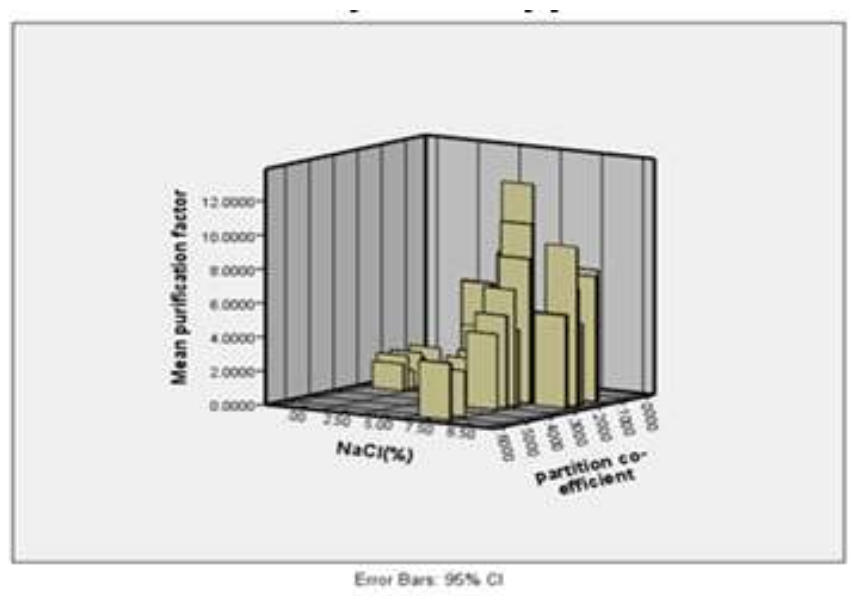

Fig.3. Effect of sodium chloride containing ATPS on partitioning coefficient and purification of papain.

Kcit20\%-PEG 16\% ATPS used.

It can be seen in Fig. 3 that while $0 \%$ and $2.5 \% \mathrm{NaCl}$ did cause low partitioning co-efficient (which means that most papain partitioned to the bottom phase), at both concentrations the purification was low. The highest purification factor was at $5 \% \mathrm{NaCl}(\mathrm{PF}=12)$ which also occurred at a low partitioning co-efficient $(\mathrm{Kpap}=0.1)$. In all the experiments, papain partitioned predominantly to the bottom (salt) phase, indicating the exclusion effect of PEG 
3350 at the concentrations used, which means that the polymer size filled all space in the top phase and forced the papain to partition to the lower phase as described by [10]. Increasing the $\mathrm{NaCl}$ content above $5 \%$ did not increase the purification factor but it increased the Kpap (caused papain to partition to both phases). This is because at this higher salt content, the electrochemical charge of the system counters the polymer exclusion effect and forces the papain to partition more to the top phase (salting-out effect). Reference [14] also found that addition of $\mathrm{NaCl}$ up-to $8.75 \%$ increased the purification factor of acid protease and also causes it to partition to the top phase. It can be seen in Fig. 4 also that 5\% $\mathrm{NaCl}$ results in the highest specific activity of the papain with the lowest partition co-efficient while other concentrations of the salt give lesser specific activity. This result concurs with findings of [15] who reported that adding $3.34 \% \mathrm{NaCl}$ improved purification of protease enzyme more than higher salt concentrations. These results seem to point that at $5 \%$ $\mathrm{NaCl}$, the polarity of the system causes the papain to partition almost exclusively to the bottom phase and also protects the activity of the papain, agreeing with the finding of [16] who also found that at $5 \%$ neutral salt $(\mathrm{KCl})$, papain partitioned almost exclusively to the bottom phase with the best activity.

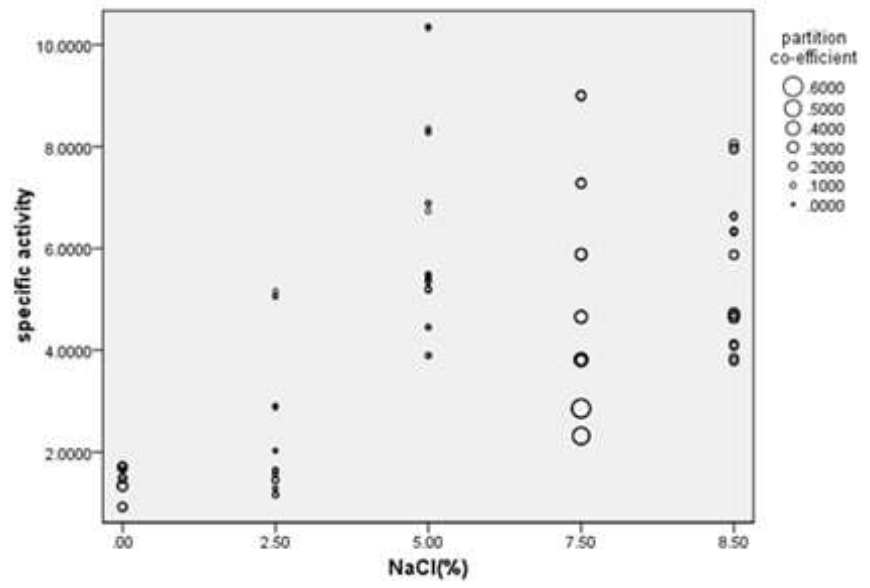

Fig.4. Specific activity and partition co-efficient of papain extracted by ATPS at different $\mathrm{NaCl}$ contents.

It can be seen in Fig. 5 that there is a linear proportional relationship between purification factor and specific activity but there is no co-relation between purification and phase volume ratio.

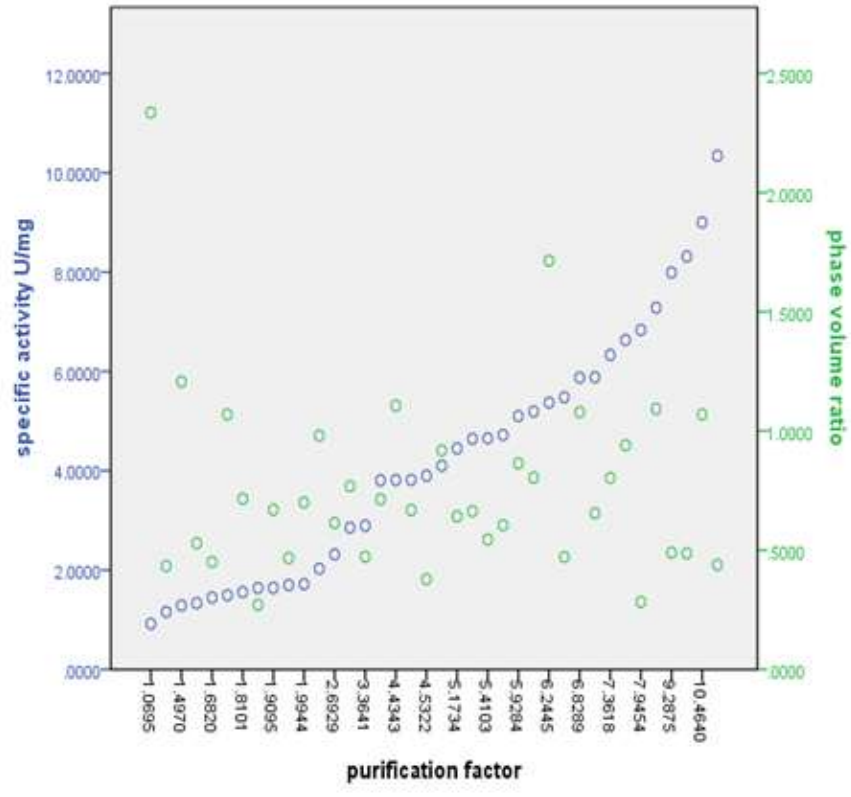

Fig.5. The co-relation of purification factor, specific activity and phase volume ratio from PEG 3350-potassium citrate ATPS
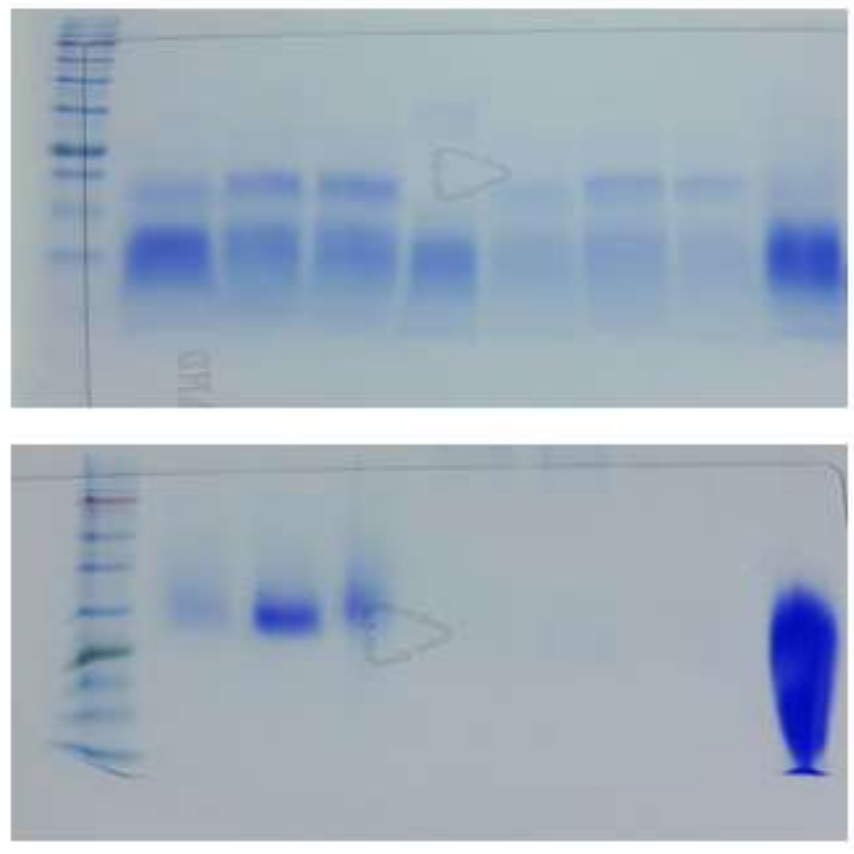

Fig.6 SDS-PAGE gel result of top phase (top) and bottom phase (bottom) from $5 \% \mathrm{NaCl}$ ATPS

Top phase lanes:1 protein marker, 2(Kcit20-PEG15), 3(Kcit16PEG15), 4(Kcit20-PEG10), 5(Kcit18-PEG 10), 6(Kcit20-PEG 14), 7(Kcit15-PEG16), 8(Kcit18-PEG12), 9(Kcit14-PEG18)

Bottom phase lanes: 1 protein marker, 2(Kcit20-PEG14), 3(Kcit20-PEG10), 4(Kcit20-PEG15)

It can be seen from the Fig. 6 that papain did partition to the bottom phase in all the experiments. It is also notable that papain was extracted at $\mathrm{pH} \mathrm{7,} \mathrm{which} \mathrm{is} \mathrm{lower} \mathrm{than} \mathrm{the} \mathrm{iso-}$ electric point of papain ( $\mathrm{pI} 8.8$ ). Many investigators have also isolated papain apart from co-extracting contaminants lower $\mathrm{pH}$ [3]-[17]. A trade-off has to be struck between the 
reduction of co-extracts and the actual activity of the target enzyme. This is because while acidic $\mathrm{pH}$ causes papain to extract with less contaminants, the acidic $\mathrm{pH}$ may lower its activity as found by [18].

\section{CONCLUSION}

The aqueous two phase extraction system is an easy, quick, cheap, environmentally-safe technique for primary separation of papain from the complex matrix of crude latex. Addition of $5 \%$ sodium chloride to the ATPS enhances the purification factor, specific activity and partition co-efficient of papain under the conditions studied. Extraction at neutral $\mathrm{pH}$ causes the papain activity to be high. Yield is highest (98\%) using Kcit20\%- PEG10\% and purification is highest (12 fold) using Kcit20\%-PEG14\%. The ATPS method can be used to partially purify protease enzymes from papaya latex in an economic and environmentally safe way.

\section{REFERENCES}

[1] Andrade-Mahecha, M. M., Morales-Rodríguez, O. \& Martínez-Correa, H. A. 2011. Study of the extraction process of papain from latex of papaya (Carica papaya) fruits cv. maradol. Acta Agronómica, 60, 218224.

[2] Bai, Z., Chao, Y., Zhang, M., Han, C., Zhu, W., Chang, Y., Li, H. \& Sun, Y. 2013. Partitioning behavior of papain in ionic liquids-based aqueous two-phase systems. Journal of Chemistry, 2013. https://doi.org/10.1155/2013/938154

[3] Nitsawang, S., Hatti-Kaul, R. \& Kanasawud, P. 2006. Purification of papain from Carica papaya latex: Aqueous two-phase extraction versus two-step salt precipitation. Enzyme and Microbial Technology, 39, 11031107.

https://doi.org/10.1016/j.enzmictec.2006.02.013

[4] Braia, M., Ferrero, M., Rocha, M. V., Loureiro, D., Tubio, G. \& Romanini, D. 2013. Bioseparation of papain from Carica papaya latex by precipitation of papain-poly (vinyl sulfonate) complexes. Protein Expression and Purification, 91, 91-95. https://doi.org/10.1016/j.pep.2013.07.008

[5] Amid, M., Manap, M. Y., Hussin, M. \& Mustafa, S. 2015. A novel aqueous two phase system composed of surfactant and xylitol for the purification of lipase from pumpkin (Cucurbita moschata) seeds and recycling of phase components. Molecules, 20, 11184-11201.

https://doi.org/10.3390/molecules200611184

[6] Amid, M., Shuhaimi, M., Sarker, M. Z. I. \& Manap, M. Y. A. 2012. Purification of serine protease from mango (Mangifera Indica $\mathrm{Cv}$. Chokanan) peel using an alcohol/salt aqueous two phase system. Food Chemistry, 132, 1382-1386.

https://doi.org/10.1016/j.foodchem.2011.11.125

[7] Dewan, S. S. 2014. Global markets for enzymes in industrial applications. Wellesley, MA 02481 USA: BCC Research.

[8] Li, S., Yang, X., Yang, S., Zhu, M. \& Wang, X. 2012. Technology prospecting on enzymes: Application,marketing and engineering Computational and Structural Biotechnology Journal, 2, 1-11. https://doi.org/10.5936/csbj.201209007

[9] Sarrouh, B., Santos, T. M., Miyoshi, A., Dias, R. \& Azevedo, V. 2012. Up-to-date insight on industrial enzymes applications and global market. Journal of Bioprocessing \& Biotechniques, 2012.

https://doi.org/10.4172/2155-9821.s4-002

[10] Babu, B. R., Rastogi, N. K. \& Raghavarao, K. S. M. S. 2008. Liquidliquid extraction of bromelain and polyphenol oxidase using aqueous two-phase system. Chemical Engineering and Processing: Process Intensification, 47, 83-89. https://doi.org/10.1016/j.cep.2007.08.006

[11] Laemmli, U. K. 1970. Cleavage of structural proteins during the assembly of the head of bacteriophage T4. Nature, 227, 680-685. https://doi.org/10.1038/227680a0

[12] Sindhu, N., Kalaivani, S. \& Regupathi, I. 2013. Bovine serum albumin partitioning in aqueous two-phase systems: effects of variables and optimization. BioProcessing Journal, 12, 29-41.
https://doi.org/10.12665/J121.Regupathi

[13] Barbosa, J. M. P., Souza, R. L., Fricks, A. T., Zanin, G. M., Soares, C. M. F. \& Lima, Á. S. 2011. Purification of lipase produced by a new source of Bacillus in submerged fermentation using an aqueous twophase system. Journal of Chromatography B, 879, 3853-3858. https://doi.org/10.1016/j.jchromb.2011.10.035

[14] Pericin, D. M., Maarev-Popovic, S. Z. \& Radulovic-Popovic, L. M. 2009. Optimization of conditions for acid protease partitioning and purification in aqueous two-phase systems using response surface methodology. Biotechnology Letters, 31, 43-47. https://doi.org/10.1007/s10529-008-9830-2

[15] Pérez, R. L., Loureiro, D. B., Nerli, B. B. \& Tubio, G. 2015. Optimization of pancreatic trypsin extraction in PEG/citrate aqueous twophase systems. Protein Expression and Purification, 106, 66-71. https://doi.org/10.1016/j.pep.2014.10.014

[16] Lu, Y. 2014. Selective extraction and purification of papain using polyethylene glycol (PEG 4000)/potassium citrate aqueous two phase. Asian Journal of Chemistry, 26, 3483-3488.

[17] Li, M., Su, E., You, P., Gong, X., Sun, M., Xu, D. \& Wei, D. 2010. Purification and in situ immobilization of papain with aqueous two-phase system. PLOS One, 5, 15168-15168. https://doi.org/10.1371/journal.pone.0015168

[18] Chaman Mehta, C., Rajesh, M. P., Sridevi, V., Divya, M. L. \& Satya, C. V. 2013. Optimisation of papain extraction by aqueous two phase system (ATPS) using response surface methodology (RSM). International Journal of Innovative Research in Science, Engineering and Technology 2, 3398-3407. 